\title{
LOSS OF MINERALS THROUGH THE SKIN OF NORMAL HUMANS WHEN SWEATING IS AVOIDED
}

\author{
BY R. H. FREYBERG AND R. L. GRANT \\ (From the Department of Internal Medicine, Medical School, University of Michigan, \\ Ann Arbor)
}

(Received for publication April 13, 1937)

Water is constantly vaporizing from the human skin surface as an important part of the heat regulatory mechanism. There are two sources for water to be vaporized: there is always vaporization which occurs as a result of the waterrich human mass existing in a relatively dry atmosphere. Water lost in this way is spoken of as "insensible loss of water." When the amount of heat carried away by this process is insufficient to maintain the homeothermic state, an additional supply of water is pumped onto the surface of the skin by the sweat glands to aid in the cooling process.

There have been many analyses of sweat; and quantitative studies of water and minerals lost through the skin during sweating have also been made $(1,2,3,4,5,6)$. Usually in studies of the latter type, one does not know how much of the total loss of water and inorganic salts is from the sweat glands. There is, in the literature, insufficient data regarding the amount of minerals lost through the skin when sweating is avoided. Mention of the most noteworthy of such data follows. McCance (7) in his studies of sodium chloride deficiency in man has taken into account the loss of minerals and nitrogen in the "insensible perspiration" both during salt restriction and recovery. Cole and Curtis (8) have measured the iodine lost through the skin in some of their iodine balance studies. Swanson and Iob (9) measured the cutaneous loss of some inorganic elements in babies 2 to 24 weeks old, and although the subjects were kept in rooms with the temperature maintained almost constant between 75 and $78^{\circ} \mathrm{F}$., the elimination of elements "in sweat" is reported. These workers determined the daily loss of sodium, potassium, calcium, phosphorus and chlorides and found that the amount of potassium lost through the skin was more than 30 per cent of the "retention" calculated in the usual manner. Neglecting loss through the skin caused consider- able error in the sodium and chloride balances also, but the calcium and phosphorus losses through the skin were negligible.

With the exception of the work of McCance (7) none of the literature cited gives us any information regarding the cutaneous loss of minerals from the healthy adult man who is not sweating. We have therefore conducted the following investigation in order to obtain such information.

\section{EXPERIMENTAL}

The subjects for the experiments were two healthy adult men who went about their usual laboratory duties with special precautions only to keep themselves cool enough to prevent sweating. Special clothing worn during the experiment consisted of medium weight cotton underwear and socks which had previously been thoroughly washed in distilled water until free of chloride. This clothing covered the entire body with the exceptions of the hands, head and neck. No special precautions were taken with the outer clothing except that new shoes were worn. Food and water were uncontrolled except that during the second experiment on Subject $B$ and for the three preceding days the intake of sodium chloride was rigidly restricted.

After a cleansing bath with soap and tap water the subject bathed in three successive changes of distilled water rubbing himself vigorously with a wash cloth during each washing, then dried himself. The wash cloth and towels used had previously been treated to remove all soluble minerals. He then donned the underwear, the socks, and his regular clothing and went about his daily routine. Twenty-four hours later the three baths in distilled water were repeated in the same way and all washings saved. The underwear, socks, wash cloth and towels used during the experiment were washed again in distilled water and all washings combined with the bath water. The combined washings and bath water were evaporated to less than a liter and the insoluble material removed by centrifuging. The precipitate was washed four times and the washings added to the soluble fraction. This solution was then evaporated to a small volume and finally made to $100 \mathrm{cc}$. Aliquots were used for the following determinations: sodium, Butler and Tuthill (10); potassium, Shohl and Bennett (11); chloride by a modified Vohlhard-Harvey titration (12) after removal of the silver chloride by filtering; sulfate was 
TABLE I

The cutaneous elimination of sodium, potassium, chloride, sulfate sulfur and nitrogen, and the urinary excretion of sodium and chloride during the 24-hour studies

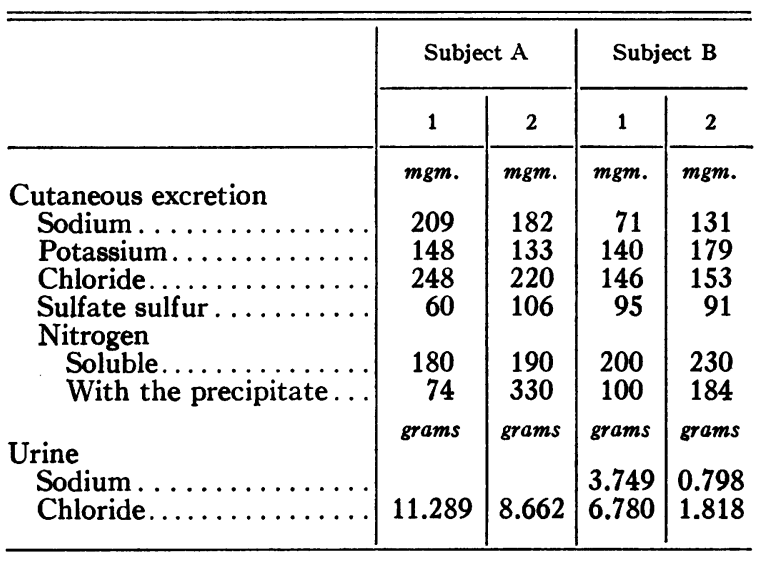

weighed as barium sulfate; nitrogen by modified Pregl micro-Kjeldahl (13); calcium, by the method of Shohl and Pedley (14); and phosphate by the Fiske-Subbarow method (15).

The same methods were used for the estimation of sodium and chloride of the urine collected during the experiment.

Two 24-hour experiments were carried out on each of the two subjects. The results of these experiments are recorded in Table $\mathrm{I}$. The sodium of the bath water varied from 71 to $209 \mathrm{mgm}$.; the potassium was 133 to $179 \mathrm{mgm}$.; the chloride was 146 to $248 \mathrm{mgm}$.; and the sulfate was 60 to $106 \mathrm{mgm}$. of sulfur. Neither calcium nor phosphate was found. No attempt was made to balance the anions and cations by the determination of other metals or acids or of $\mathrm{pH}$. In the precipitate, which is made up of lint from the towels and clothing along with variable amounts of cellular debris and hair, the amount of nitrogen would be expected to vary considerably. The nitrogen in solution was found to be 180 to $230 \mathrm{mgm}$.

\section{DISCUSSION}

It had previously been found by Wiley, Wiley and Waller (16) that Subject B over a period of 77 days excreted an average of $37 \mathrm{mgm}$. of sodium per day. The same subject lost 71 and 131 mgm. of sodium daily through the skin during the two experiments reported here. These values illustrate the relative importance of measuring the sodium lost by the two paths of excretion. During the low intake of sodium chloride, particularly, (second experiment on Subject B), cutaneous excretion cannot be disregarded, for in this experiment more than 14 per cent of the total urinary and cutaneous sodium is lost through the skin.
This experiment also shows that the loss of sodium, chloride and other minerals through the skin does not vary with the intake of sodium chloride or with the amount in the urine.

It is interesting to compare our findings with those reported by McCance (7). During a " recovery period" of 5 days one of McCance's subjects lost $370 \mathrm{mgm}$. of sodium and $670 \mathrm{mgm}$. of chloride in the "insensible perspiration." These values are equivalent to $74 \mathrm{mgm}$. of sodium and $134 \mathrm{mgm}$. of chloride per day. Another subject lost $98 \mathrm{mgm}$. of potassium per day in her " insensible perspiration." The amounts are of the same order but lower than those reported here.

Even though special care was taken to avoid sweating, we wished to prove that the inorganic elements found in these studies did not come from unnoticed sweat. Further, we wished to eliminate the possibility that inorganic salts might have reached the garments worn from a source other than the skin. Accordingly a 12-hour experiment was carried out while Subject B lay nude on a rubber sheet in a secluded room in which the temperature was maintained at 25 to $28^{\circ} \mathrm{C}$. During this period there was no detectable moisture on the skin. The insensible loss of weight for this 12-hour period, determined by the method of Newburgh, Wiley and Lashmet (17), was $39 \overline{7}$ grams. Sixty-two grams were lost due to the difference in weight between outgoing $\mathrm{CO}_{2}$ and incoming $\mathrm{O}_{2}$. The remainder, 335 grams, was water vaporized from the lungs and skin. Under the prevailing conditions about $2 / 3$ of the water vapor comes from the skin, thus about 225 grams of water was vaporized from the skin. It carried with it $32 \mathrm{mgm}$. of sodium, $47 \mathrm{mgm}$. of potassium, $53 \mathrm{mgm}$. of chloride and $34 \mathrm{mgm}$. of sulfate sulfur. Comparing these 12 -hour values obtained during rest with those for Subject $B$ in Table $I$, and realizing that the insensible loss of water is considerably greater when the subject is up and about, it is obvious that little if any of the 24-hourly values of the substances studied could have come from sweat or sources other than the skin.

According to Fishberg and Bierman (5) sweat contains about $1880 \mathrm{mgm}$. of sodium, $3000 \mathrm{mgm}$. of chloride and $200 \mathrm{mgm}$. of potassium per liter. Then insensible water contains a much lower con- 
centration of sodium and chloride and approximately the same concentration of potassium as is found in sweat. The higher $\mathrm{K}: \mathrm{Na}$ ratio of insensible perspiration as compared with sweat has been pointed out previously $(4,6)$.

\section{SUMMARY}

Experiments were conducted to measure the loss of certain inorganic elements through the skin of two healthy adult men while precautions were taken to prevent sweating. No calcium or phosphorus was found. The 24-hourly eliminations of the other substances studied were: sodium 71 to 209 mgm., potassium 133 to $179 \mathrm{mgm}$., chloride 146 to $248 \mathrm{mgm}$. and sulfate sulfur 60 to $106 \mathrm{mgm}$. The cutaneous loss of sodium and chloride did not vary with the intake or urinary output of sodium chloride.

The amounts involved are of considerable importance for the accurate determination of the exchange of these elements as commonly done in mineral "balance" studies, and unless the cutaneous excretions are actually measured, suitable additions should be made to the outgo to correct for losses through the skin.

The authors gratefully acknowledge the many helpful suggestions made by Dr. L. H. Newburgh throughout this study.

\section{BIBLIOGRAPHY}

1. Favre, $P$. A., Recherches sur la composition chimique de la sueur chez l'homme. Arch. gén. de med. Par. 1853, 2, 1.

2. Camerer, W., Utber die chemische Zusammensetzung des Schweisses. Ztschr. f. Biol., 1901, 41, 271.

3. (a) Talbert, G. A., The ash of human sweat produced by heat and work. Am. J. Physiol., 1923, 63, 350.

(b) Talbert, G. A., and Haugen, C. O., Simultaneous study of constituents of the sweat, urine and blood, also gastric acidity and other manifestations resulting from sweating. I. Chlorides. Am. J. Physiol., 1927, 81, 74. (c) Talbert, G. A., Silvers, S., and Johnson, W., Simultaneous study of constituents of the sweat, urine and blood, also gastric acidity and other manifestations resulting from sweating. II. Total nitrogen of sweat and urine: total nonprotein nitrogen of blood. Am. J. Physiol., 1927, 81, 81.

4. Hancock, W., Whitehouse, A. G. R., and Haldane, J. S., The loss of water and salts through the skin, and the corresponding physiological adjustments. Proc. Roy. Soc., s. B., 1929, 105, 43.

5. Fishberg, E. H., and Bierman, W., Acid-base balance in sweat. J. Biol. Chem., 1932, 97, 433.

6. McSwiney, B. A., The composition of human perspiration. Proc. Roy. Soc. Med., 1934, 27, 839.

7. McCance, R. A., Experimental sodium chloride deficiency in man. Proc. Roy. Soc., s. B., 1936, 119, 245.

8. Cole, V. V., and Curtis, G. M., Human iodine balance. J. Nutrition, 1935, 10, 493.

9. Swanson, W. W., and Iob, L. V., Loss of minerals through the skin of infants. Am. J. Dis. Child., 1933, 45, 1036.

10. Butler, A. M., and Tuthill, E., An application of the uranyl zinc acetate method for determination of sodium in biological material. J. Biol. Chem., 1931, 93, 171.

11. Shohl, A. T., and Bennett, H. B., A micro method for the determination of potassium as iodoplatinate. J. Biol. Chem., 1928, 78, 643.

12. Peters, J. P., and Van Slyke, D. D., Quantitative Clinical Chemistry. Volume II. Methods. Williams and Wilkins Co., Baltimore, 1932, p. 833.

13. Ibid., p. 530 .

14. Shohl, A. T., and Pedley, F. G., A rapid and accurate method for calcium in urine. J. Biol. Chem., 1922, 50, 537.

15. Fiske, C. H., and Subbarow, Y., The colorimetric determination of phosphorus. J. Biol. Chem., 1925, 66, 375.

16. Wiley, F. H., Wiley, L. L., and Waller, D. S., The effect of the ingestion of sodium, potassium, and ammonium chlorides and sodium bicarbonate on the metabolism of inorganic salts and water. J. Biol. Chem., 1933, 101, 73.

17. Newburgh, L. H., Wiley, F. H., and Lashmet, F. H., A method for the determination of heat production over long periods of time. J. Clin. Invest., 1931, 10,703 . 